\title{
Protocols of a diagnostic study and a randomized controlled non-inferiority trial comparing televisits vs standard in-person outpatient visits for narcolepsy diagnosis and care: TElemedicine for NARcolepsy (TENAR)
}

Francesca Ingravallo ${ }^{1}$, Luca Vignatelli $i^{2^{*}}$ (D, Uberto Pagotto ${ }^{1}$, Stefano Vandi ${ }^{2,3}$, Monica Moresco ${ }^{2,3}$, Anastasia Mangiaruga ${ }^{1}$, Claudia Oriolo ${ }^{1}$, Corrado Zenesini ${ }^{2}$, Fabio Pizza ${ }^{2,3}$ and Giuseppe Plazzi ${ }^{2,3}$

\begin{abstract}
Background: Narcolepsy is a rare chronic sleep disorder that typically begins in youth. Excessive daytime sleepiness is the main disabling symptom, but the disease is often associated with severe endocrine-metabolic and psychosocial issues, worsened by a long diagnostic delay, requiring a multidisciplinary approach. The scarcity of reference Sleep Centres forces the patient and family to travel for seeking medical consultations, increasing the economic and psychosocial burden of the disease. Growing evidence suggests that Telemedicine may facilitate patient access to sleep consultations and its non-inferiority in terms of patient satisfaction, adherence to treatment, and symptom improvement for sleep disorders. However, Telemedicine clinical and economic benefits for patients with narcolepsy are still unknown.

Methods: TENAR is a two-part project, including: 1. a cross-sectional study (involving 250 children and adults with suspected narcolepsy) evaluating the accuracy of Teletriage (i.e., a synchronous live interactive sleep assessment through a Televisit) for narcolepsy diagnosis compared to the reference standard; and 2. a twoarm, parallel, open randomized controlled trial (RCT) to demonstrate the non-inferiority of the multidisciplinary care of narcolepsy through Televisits versus standard care. In this RCT, 202 adolescents (> 14 y.o.) and adults with narcolepsy will be randomly allocated (1:1 ratio) either to Televisits via videoconference or to standard in-person outpatient follow-up visits (control arm). The primary outcome is sleepiness control (according to the Epworth Sleepiness Scale). Secondary outcomes are other symptoms control, compliance with treatment, metabolic control, quality of life, feasibility, patient and family satisfaction with care, safety, and disease-related costs. At baseline and at 12 months, patients will undergo neurologic, metabolic, and psychosocial (Continued on next page)
\end{abstract}

\footnotetext{
* Correspondence: I.vignatelli@ausl.bologna.it

${ }^{2}$ IRCCS Istituto delle Scienze Neurologiche di Bologna, Via Altura 3, Bologna, Italy

Full list of author information is available at the end of the article
}

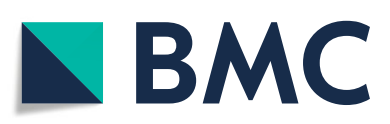

( ) The Author(s). 2020 Open Access This article is licensed under a Creative Commons Attribution 4.0 International License, which permits use, sharing, adaptation, distribution and reproduction in any medium or format, as long as you give appropriate credit to the original author(s) and the source, provide a link to the Creative Commons licence, and indicate if changes were made. The images or other third party material in this article are included in the article's Creative Commons licence, unless indicated otherwise in a credit line to the material. If material is not included in the article's Creative Commons licence and your intended use is not permitted by statutory regulation or exceeds the permitted use, you will need to obtain permission directly from the copyright holder. To view a copy of this licence, visit http://creativecommons.org/licenses/by/4.0/. The Creative Commons Public Domain Dedication waiver (http://creativecommons.org/publicdomain/zero/1.0/) applies to the data made available in this article, unless otherwise stated in a credit line to the data. 


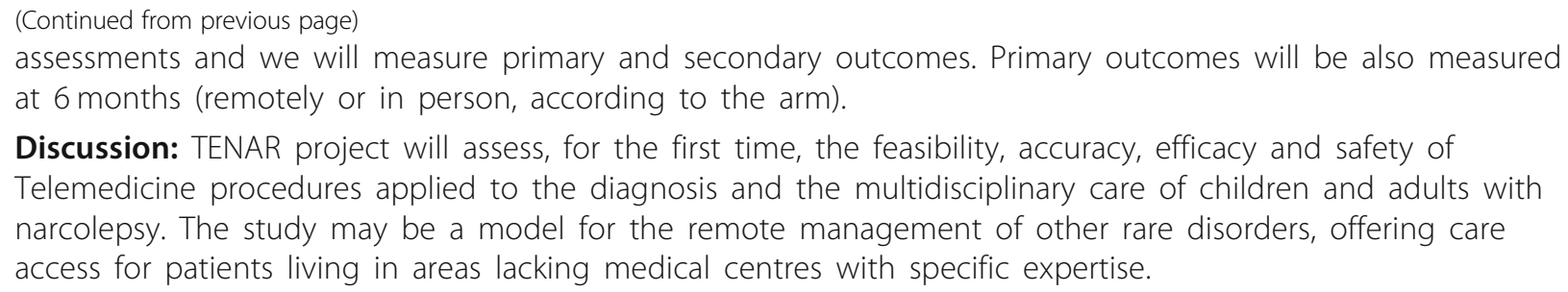

Trial registration: Number of the Tele-multidisciplinary care study NCT04316286. Registered 20 March 2020.

Keywords: Telemedicine, Televisit, Diagnosis, Management, Care, Sleep disorders, Narcolepsy, Sleepiness, Quality of life

\section{Background}

Narcolepsy is a rare chronic disorder of hypersomnolence [1] with excessive daytime sleepiness (EDS) as the main disabling symptom. The estimated prevalence in the general population is of $0.02-0.067 \%$ [2]. Narcolepsy onset occurs between childhood and young adulthood [3]. However, patients often experience an extended diagnostic delay (14 years in Europe) [4] that may be associated with misdiagnosis and inappropriate resource utilization, increasing the psycho-social impact of the disease [3,5]. Quality of life and social activities are profoundly impaired in both adults and children [6,7], and patients need frequent and timely counselling to adjust behavioural and pharmacological treatments. High direct and indirect disease-related costs are reported [8-10]. Metabolic (obesity, diabetes, precocious puberty) and psychiatric comorbidities (mood, anxiety, and eating disorders) are additional common features in narcolepsy [11], and require a multidisciplinary approach. To our knowledge, the 'Centro Narcolessia' (CN) of Bologna, located in the Emilia-Romagna Region in the north of Italy, is the only Italian centre offering a multidisciplinary management of narcolepsy (covering sleep, metabolic, psychological, and psychosocial aspects for both paediatric and adult patients), avoiding multiple referrals. The $\mathrm{CN}$ is the first Italian centre in terms of number of assisted patients, $71 \%$ of whom come from outside the Emilia-Romagna Region (the most distant one comes from Pantelleria, an island $1553 \mathrm{~km}$ far from the CN). Unmet patients' needs at regional level force them to undertake long journeys to seek for consultations, with consequent delayed access to diagnosis and care and high direct and indirect disease-related costs, possibly worsening the control of disease symptoms and the prevention of drug side effects. Indeed, according to the Authors' clinical practice experience, patients may refrain from scheduled outpatient visits due to high costs to reach the Sleep centre.

In this regard, Telemedicine (TM) is one of the most promising approaches. TM is the "practice of medicine using electronic communications, information technology, or other means between a licensee in one location and a patient in another location" [12]. The American Academy of Sleep Medicine supports TM as a means of advancing patient health by improving access to the expertise of qualified Sleep Medicine specialists [13]. TM includes Televisits (TVs) via videoconference, a synchronous live interactive TM visit, in which "patients and providers are separated by distance but interact in real-time utilizing videoconferencing as the core technology" [13].

Several studies about the impact and outcomes of Sleep TM investigated various TM applications (e.g., TVs, home sleep test devices or telemetric titration methods, etc.) for the diagnosis, monitoring, treatment, education and followup of obstructive sleep apnoea [14-17]. Despite the scarceness of randomized controlled trials (RCT), the available studies suggest the non inferiority of TM vs in-person care in terms of patient satisfaction, adherence to treatment, and symptomatic improvement [17]. Moreover, some studies confirm that TM has the potential to facilitate patient access to sleep consultations [18-21]. However, clinical and economic benefits of Sleep TV procedures is still uncertain [22], and its impact, with the exception of stroke, has been rarely explored in the neurology field [23]. In particular, the potential of this innovative approach for the diagnosis and management of narcolepsy is still unknown. Robust randomized trials are needed to understand the impact of Sleep TM on patient outcomes, and health-care system accessibility [17].

The TENAR (TElemedicine for NARcolepsy) project will assess for the first time Sleep TM procedures for children and adults with narcolepsy. In particular, the project will assess the feasibility, accuracy, efficacy and safety of TVs applied to the diagnostic process and the multidisciplinary care of narcolepsy. The TENAR project combines the patient-oriented outcomes research approach with the theoretical approach of "move the healthcare where it really needs" [24] through TM and mobile internet devices.

\section{Aims}

TENAR is a two-part project aiming at: 1 . assessing the accuracy of TV for the diagnosis of narcolepsy (Tele-triage study) in children and adults with suspected narcolepsy; and 2. demonstrating the non-inferiority for EDS control of the multidisciplinary management through TVs vs standard in-person outpatient follow-up visits, 
while monitoring patient-centred outcomes (Tele-multidisciplinary care - TMC - study). The TENAR project is endorsed by the Italian Narcolepsy and Hypersomnias association (AIN onlus, www.narcolessia.org).

\section{Methods/design}

TENAR is a monocentric project designed by the $\mathrm{CN}$ ('Centro Narcolessia' - Narcolepsy Centre), part of IRCCS Istituto delle Scienze Neurologiche di Bologna, an academic hospital, in the city of Bologna, Italy. The coordination of the project, data collection, management, analysis, and interpretation of data, writing of the reports will be performed by the $\mathrm{CN}$. All Authors will have access to the final dataset.

\section{Tele-triage study \\ Study design and outcomes}

The Tele-triage study aims at assessing the diagnostic accuracy of a sleep medicine assessment through a TV of patients with suspected narcolepsy, by means of a crosssectional design. The index text will be the diagnostic judgment after a TV by a sleep specialist according to three levels: "probable narcolepsy", "possible narcolepsy" or "excluded narcolepsy". The reference standard will be the final diagnosis ("confirmed narcolepsy" or "excluded narcolepsy"), established after a standard work-up for the diagnosis of narcolepsy and other sleep disorders with EDS complaint according to the International Classification of Sleep Disorders (ICSD-3) criteria [1] (i.e. symptoms and objective in laboratory assessment, eventually including cerebrospinal fluid orexin level measurement). A physician blinded to the initial diagnostic suspicion will establish the final diagnosis on the basis of patients records, including test results. The primary outcome is the diagnostic accuracy (sensitivity, specificity); the secondary outcome is the interobserver agreement between sleep experts on diagnostic orientation (according to 3 levels: "probable narcolepsy", "possible narcolepsy", or "narcolepsy excluded") after inperson or TV assessment respectively.

\section{Participants, setting and procedures}

Children (any age) and adults admitted to $\mathrm{CN}$ outpatient clinic of the IRCCS Istituto delle Scienze Neurologiche di Bologna, Italy, for suspected narcolepsy will be invited to participate. After informed consent procedure, participants will undergo a sleep assessment through inperson office visit first or TV first, by two independent sleep experts. Both the type of visit and the examiner will be assigned randomly. During TV, patients will use a tablet (in a dedicated $\mathrm{CN}$ room) and the sleep expert an in-office PC (in a different room). In case of children, a parent/caregiver will be present at both assessments. The sleep assessment for suspected narcolepsy consists of a reliable semi-structured interview on narcolepsy symptoms [25].

At the end of the assessment, each examiner will express his/her diagnostic orientation ("probable", "possible" or "excluded" diagnosis of narcolepsy). In the following months, all participants will undergo the reference standard work-up according to clinical practice.

\section{Sample size and statistical considerations}

Two hundred and fifty patients are necessary to prove the desired sensitivity of $94 \%$ (CI lower limit) of TV, keeping CI lower limit of specificity at $73 \%$, expecting $40 \%$ prevalence of narcolepsy at the $\mathrm{CN}$ outpatient clinic referral. Interobserver reliability will be calculated by kappa statistics, which is the ratio of the observed agreement beyond chance to the potential agreement, according to the formula proposed by Fleiss [26]. Kappa values will be interpreted according to conventional groups $(0.0-0.20=$ slight agreement, $0.21-0.40=$ fair, $0.41-0.60=$ moderate, $0.61-$ $0.80=$ substantial, $0.81-1.00=$ almost perfect) [27] .

\section{Tele-multidisciplinary care (TMC) study Study design and outcomes}

The TMC study is a 12-month, two-arm, parallel, open RCT aiming to demonstrate the non-inferiority for EDS control of the multidisciplinary care of narcolepsy through TVs versus standard in-person follow-up care (Fig. 1). Primary outcome is EDS control (according to the Epworth Sleepiness Scale, ESS [28]). Secondary outcomes are the following: other symptoms control, compliance with treatment, metabolic control, quality of life, feasibility, patient and family satisfaction with care, safety, and disease-related costs. Primary and secondary outcomes, and related measures and timepoints for data collection are summarized in Table 1.

\section{Population, intervention and procedures}

Adolescents ( $\geq 14$ years old) and adults with a diagnosis of narcolepsy according to ICSD-3 [1] criteria soon after the diagnosis ("incident") or with established diagnosis ("prevalent" subjects) in charge at the CN of the IRCCS Istituto delle Scienze Neurologiche di Bologna, Italy, and able to provide consent are eligible. Exclusion criteria are the following: major psychiatric disorders; inability to read, write, or using a tablet; and no Internet access.

Patients who provide informed consent will undergo the following baseline in-person assessment by different experts through standardized tools (see Table 1):

- sleep assessment;

- endocrine/metabolic assessment, with measurement of weight, height, waist circumference, blood pressure, heart rate; and 


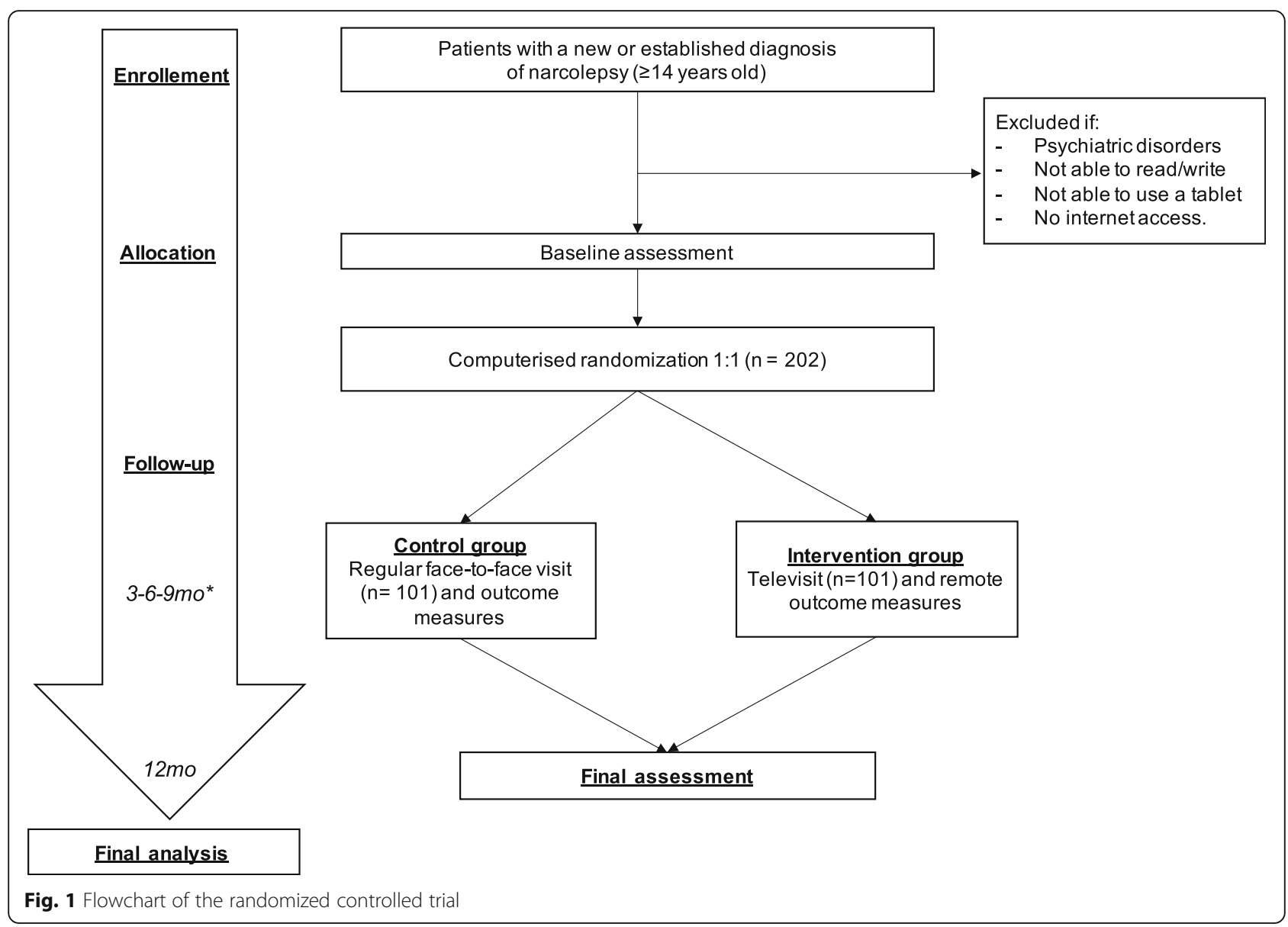

- a counselling session on the psychosocial impact of narcolepsy.

Patients will also be requested to complete a physical activity questionnaire [29], and to provide a 24-h food diary. In addition, a blood sample will be collected for a metabolic (lipid and glucose profile, and thyroid function) evaluation.

After baseline procedures, patients will be consecutively randomly allocated in 1:1 ratio either to TMC via videoconference or to standard in-person follow-up inoffice visits (control arm). The randomization list (stratified for three groups: children, adults with incident condition, adults with prevalent condition) and allocation will be generated by an automatic web-based system after inclusion.

The TMC will consist of scheduled TVs through a tablet and remote data collection through an ad hoc designed electronic case report form (e-CRF). A videoconference service will be used. The TV will be performed aiming at assessing the patient's condition, and his/her need/response to treatments. TVs will end with therapeutic prescriptions according to usual practice, until the next follow-up TV. A formal report of the sleep assessment through TV will be sent by mail to the patient. The standard in-person follow-up care consists in scheduled (3-6-9 months) usual in-office visits, performing the same assessments, data collection and therapeutic prescriptions according to usual practice. The scheduling of follow-up TVs or in-person visits (at 3-6-9 months) will be based on the patient's condition and needs (see Table 1).

\section{Sample size and statistical considerations}

A total of 176 patients (88 per arm) are required to prove that the $95 \%$ lower limit of one-sided CI will be above the non-inferiority limit of - 1.5 ESS points difference (standard deviation of 4 ), with $80 \%$ of power. A previous RCT used a non-inferiority margin of 2 ESS points and $80 \%$ as minimal power to compare pitolisant versus modafinil in patients with narcolepsy [30]. As the TMC study will not test drugs, we decided to adopt a stricter margin (1.5 ESS points). The standard deviation value $( \pm 4)$ was based on the Italian validation study of ESS [28]. Considering 15\% of dropouts, the sample was enlarged to 202 (101 per arm). Repeated measures ANOVA will be used to compare EDS between groups at baseline and after 1-yr of follow-up. 
Table 1 Primary and secondary outcomes, measures and timepoints

\begin{tabular}{|c|c|c|}
\hline Outcomes & Measures & Timepoints (months) \\
\hline \multicolumn{3}{|l|}{ Primary } \\
\hline EDS & $\begin{array}{l}\text { ESS (adults) [28] } \\
\text { ESS-CHAD [32] (adolescents) }\end{array}$ & $\begin{array}{l}0,3,6,9,12 \text { incident patients } \\
0,6,12 \text { prevalent patients }\end{array}$ \\
\hline \multicolumn{3}{|l|}{ Secondary } \\
\hline Other symptoms & $\begin{array}{l}\text { Cataplexy diary, NSS [33], BDI [34], } \\
\text { STAI [35] (adults) } \\
\text { CDI2 [36], MASC [37] (adolescents) } \\
\text { Global Impression Scale [38] (physicians) }\end{array}$ & $\begin{array}{l}0,3,6,9,12 \text { incident patients } \\
0,6,12 \text { prevalent patients }\end{array}$ \\
\hline Compliance to treatment & Clinical consultation & $\begin{array}{l}0,3,6,9,12 \text { incident patients } \\
0,6,12 \text { prevalent patients }\end{array}$ \\
\hline Weight & $\begin{array}{l}\text { Standard weight scale provided to } \\
\text { each patient }\end{array}$ & $\begin{array}{l}0,3,6,9,12 \text { incident patients } \\
0,6,12 \text { prevalent patients }\end{array}$ \\
\hline Lipidic/glycaemic control* & Laboratory tests & 0,12 \\
\hline Caloric intake & Food diary & $\begin{array}{l}0,12[0,3,6,9,12 \text { patients with } \\
\text { metabolic problems }]\end{array}$ \\
\hline Physical activity & Short-IPAQ [29] & $\begin{array}{l}0,12[0,3,6,9,12 \text { patients with } \\
\text { metabolic problems }]\end{array}$ \\
\hline Satisfaction index & CoTenar (patients and caregiver) & 6,12 \\
\hline Quality of life & $\begin{array}{l}\text { SF-36 (adults) [39] } \\
\text { PedsQL [40] (adolescents) }\end{array}$ & $0,6,12$ \\
\hline Number (\%) of full dropouts & & At the time of censorship \\
\hline $\begin{array}{l}\text { Number (\%) of partial dropouts } \\
\text { (patients changing procedure) }\end{array}$ & & At the time of arm change \\
\hline Adverse drug reactions & Clinical consultation & $\begin{array}{l}0,3,6,9,12 \text { incident patients } \\
0,6,12 \text { prevalent patients }\end{array}$ \\
\hline Costs and accidents & Interview (patients and caregivers) & $0,6,12$ \\
\hline Other feasibility indexes & $\begin{array}{l}\text { Failure system report (physicians } \\
\text { and patients) }\end{array}$ & After each TV \\
\hline
\end{tabular}

*Glucose, insulin, HbA1c, triglycerides, total, LDL and HDL cholesterol, TSH, glycaemia, insulin, glycated haemoglobin, HDL, triglycerides, total, LDL, uricemia, TSH, FT4, FT3, complete blood count, AST, ALT, gamma-GT, alkaline phosphatase, creatinine. ** Adapted from CoSM-S [41]

\section{Safety assessments and monitoring}

Patients may face difficulties in accepting TMC for the fear of less accurate assistance or for barriers in the use of mobile technology. We plan to cooperate with AIN for the recruitment and education (e.g., tutorial activities for the tablet use) in order to avoid inappropriate exclusion of patients with technology barriers. The patient, contacting a provider through the tablet, 3-h/week, may request on-call TVs. The same availability will be provided to patients included in the control arm.

With patient consent, the first TVs will be recorded in order to assess the experts' fidelity to the protocol procedures. Recordings will be destroyed at the end of the assessment. $\mathrm{CN}$ will be in charge of monitoring.

\section{Data entry, coding, security, and storage}

All data will be entered electronically in an ad-hoc design web-based e-CRF. This will be done directly by the patient filling in the forms before each visit (e-questionnaires), or during the visits by the physicians (clinical assessment). The e-CRF is designed and validated for data security and storage according to international standards (US FDA: 21 CFR Part 11; EU GMP: Annex 11; ICH/GCP; VICH/GCP; GAMP 5; GDPR). Personal information about participants will be processed in accordance with the GDPR and national regulation on data protection.

\section{Ethical approval and informed consent procedures}

The study will be conducted in accordance with Helsinki declaration. The Independent Ethics Committee of Area Vasta Emilia Centro (CE-AVEC) approved both the Tele-Triage study and the TMC study (number 18034120_2018_sper and 18,033-121_2018_sper respectively). Signed informed consent form will be obtained by the sleep experts prior to recruitment. Consent for patients< 18 y.o. will be provided by their parents. Separate assent forms will be signed by minors (aged 12-17 and aged 14-17 for Tele-Triage study and TMC study respectively). Both participants and parents/guardians will be 
free to withdraw their consent for participation at any time. Participants may request to be informed about results of the study once the study is finished. The results of the TENAR project will be communicated during scientific meetings and AIN's meetings, and through publication in peer-reviewed journals. We will not involve a professional writer.

\section{Discussion}

Narcolepsy is a rare chronic disease with complex needs encompassing medical and psychosocial aspects. The TENAR project will provide, for the first time, evidence about the feasibility, accuracy, efficacy, and safety of TM procedures applied to the diagnosis and the multidisciplinary care of children and adults with narcolepsy. The project combines a multidisciplinary patient-centered approach to narcolepsy with the possibility of screening and following up patients sparsely living across the country by erasing distance-related barriers. We hypothesize that the Tele-triage and the TMC will guarantee accurate, efficient and safe screening and care of patients with narcolepsy.

First, we expect that the Tele-triage procedure will have a good diagnostic accuracy, namely a high sensitivity in capturing possible patients with narcolepsy. This procedure may ease patient access to highly qualified Sleep centres, reducing the diagnostic gap and its detrimental consequences. This is paramount for people suffering from narcolepsy, especially for the youngest ones. Delayed diagnosis, misdiagnoses, and multiple referrals before receiving a proper diagnosis are frequent in narcolepsy [31] and have negative consequences for untreated patients, their family and the healthcare system. Indeed, the diagnostic gap aggravates the psychosocial and economic burden of the disease [3, 31], while a prompt diagnosis of narcolepsy at a young age seems to reduce the future socio-economic burden of the disease [5].

Second, we expect that the TMC will improve patientcentred outcomes without worsening EDS control. TMC guarantees a face-to-face interaction between patients and physicians working in qualified third level centres care, overcoming the geographical barriers.

If the study results will be in line with our hypotheses, the TENAR study procedures will potentially improve access to a timely diagnosis and care for patients with narcolepsy in Italy and other countries. Given the Directive 2011/24/EU on the application of patients' rights in cross-border healthcare (http://data.europa.eu/eli/ dir/2011/24/oj), and the European Reference Networks for rare diseases (http://www.ern-rnd.eu/), the TENAR project approach may also be a model for the management of other rare disorders, and will offer solutions for remote care of patients residing in areas lacking of specific expertise.

\section{Abbreviations}

BDI: Beck Depression Inventory; CDI2: Children Depression Inventory-2; EDS: Excessive daytime sleepiness; ESS: Epworth Sleepiness Scale; ESSCHAD: Epworth Sleepiness Scale for Children \& Adolescents; ICSD3: International Classification of Sleep Disorders third edition; MASC: Multidimensional Anxiety Scale for Children; NSS: Narcolepsy Severity Scale; PedsQL: Paediatric Quality of Life Inventory; SF-36: Short Form-36 health survey; Short-IPAQ: Short International Phisycal Activity Questionnaire; STAI: State-Trait Anxiety Inventory; TM: Telemedicine; TV: Televisit; VC: Video consultation

\section{Acknowledgements}

We thank Dr. Nicola Bianchi and Dr. Chiara Laposata for their kind help in literature search. The Italian Association of Narcoleptic and Hypersomnias Patients (Associazione Italiana Narcolettici e Ipersonni) endorsed the study.

\section{Authors' contributions}

FI, LV, UP, FP, GP, SV and CZ have made substantial contribution to conception and design of the study. LV, AM, MM, CO and SV were responsible for project implementation. FI, AM, LV and FP drafted the manuscript. All Authors read and approved the final manuscript.

\section{Funding}

The TENAR project was funded by the Italian Ministry of Health (project code: RF-2016-02364742), after undergoing a peer-reviewed grant award process by the funding body. The funding body had no role in the design of this study and will not have any role during its execution, analyses, interpretation of the data, or decision to submit results.

\section{Availability of data and materials}

This manuscript does not contain any data. At the end of the study, datasets and materials will be available from the corresponding Author on reasonable request.

\section{Ethics approval and consent to participate}

The Independent Ethics Committee of Area Vasta Emilia Centro (CE-AVEC) approved both the Tele-Triage study and the TMC study (number 18034120_2018_sper and 18033-121_2018_sper respectively). All participants will sign an informed consent form prior to recruitment. Consent for patients< 18 y.o. will be provided by their parents/guardians. Separate assent forms will be signed by minors.

\section{Consent for publication}

Not applicable.

\section{Competing interests}

The Authors declare that they have no competing interests.

\section{Author details}

${ }^{1}$ Department of Medical and Surgical Sciences (DIMEC), University of Bologna, Bologna, Italy. ${ }^{2}$ IRCCS Istituto delle Scienze Neurologiche di Bologna, Via Altura 3, Bologna, Italy. ${ }^{3}$ Department of Biomedical and Neuromotor Sciences (DIBINEM), University of Bologna, Bologna, Italy.

Received: 13 April 2020 Accepted: 3 May 2020

Published online: 11 May 2020

\section{References}

1. Medicine AA of S. International classification of sleep disorders-third edition (ICSD-3). Darien, Am Acad Sleep Med. 2014;

2. Wijnans L, Lecomte C, de Vries C, Weibel D, Sammon C, Hviid A, et al. The incidence of narcolepsy in Europe: before, during, and after the influenza a(H1N1)pdm09 pandemic and vaccination campaigns. Vaccine [Internet] 2013;31(8):1246-1254. Available from: https://doi.org/10.1016/j.vaccine.2012. 12.015 .

3. Thorpy MJ, Krieger AC. Delayed diagnosis of narcolepsy : characterization and impact. Sleep Med [Internet] 2014;15(5):502-507. Available from: https:// doi.org/10.1016/j.sleep.2014.01.015.

4. Luca G, Haba-Rubio J, Dauvilliers Y, Lammers GJ, Overeem S, Donjacour CE, et al. Clinical, polysomnographic and genome-wide association analyses of 
narcolepsy with cataplexy: a European narcolepsy network study. J Sleep Res. 2013;22(5):482-95.

5. Ingravallo F, Gnucci V, Pizza F, Vignatelli L, Govi A, Dormi A, et al. The burden of narcolepsy with cataplexy: how disease history and clinical features influence socio-economic outcomes. Sleep Med [Internet]. 2012; 13(10):1293-1300. Available from: https://doi.org/10.1016/j.sleep.2012.08.002.

6. Plazzi G, Clawges HM, Owens JA. Clinical characteristics and burden of illness in pediatric patients with narcolepsy. Pediatr Neurol [internet]. 2018; 85:21-32. Available from: https://doi.org/10.1016/j.pediatrneurol.2018.06.008.

7. Raggi A, Plazzi G, Ferri R. Health-related quality of life in patients with narcolepsy: a review of the literature. J Nerv Ment Dis. 2019;207(2):84-99.

8. Carls G, Reddy SR, Broder MS, Tieu R, Villa KF, Profant J, et al. Burden of disease in pediatric narcolepsy: a claims-based analysis of health care utilization, costs, and comorbidities. Sleep Med [internet]. 2020;66:110-118. Available from: https://doi.org/10.1016/j.sleep.2019.08.008.

9. Flores NM, Villa KF, Black J, Chervin RD, Witt EA. The humanistic and economic burden of narcolepsy. J Clin Sleep Med. 2016;12(3):401-7.

10. Thorpy MJ, Hiller G. The medical and economic burden of narcolepsy: implications for managed care. Am Heal Drug Benefits. 2017;10(5):233-40.

11. Bassetti CLA, Adamantidis A, Burdakov D, Han F, Gay S, Kallweit U, et al. Narcolepsy-clinical spectrum, aetiopathophysiology, diagnosis and treatment. Nat Rev Neurol. 2019;15(9):519-39.

12. Bruyneel M. Telemedicine in the diagnosis and treatment of sleep apnoea. 2019;(1):1-10. Available from: https://doi.org/10.1183/16000617.0093-2018.

13. Singh J, Badr MS, Diebert W, Epstein L, Hwang D, Karres V, et al. American Academy of Sleep Medicine ( AASM ) Position Paper for the Use of Telemedicine for the Diagnosis and Treatment of Sleep Disorders An American Academy of Sleep Medicine Position Paper 2015;11(10):1187-1198.

14. Bruyneel M, Broecke S Van Den, Libert W, Ninane V. Real-time attended home-polysomnography with telematic data transmission. Int J Med Inform [Internet] 2013;82(8):696-701. Available from: https://doi.org/10.1016/j. ijmedinf.2013.02.008.

15. Lugo V, Villanueva JA, Garmendia O, Montserrat JM. The role of telemedicine in obstructive sleep apnea management. Expert Rev Respir Med. 2017;11(9):699-709.

16. Murphie $\mathrm{P}$, Little S, Mckinstry B, Pinnock H. Remote consulting with telemonitoring of continuous positive airway pressure usage data for the routine review of people with obstructive sleep apnoea hypopnoea syndrome : A systematic review 2017:0(0):1-9.

17. Zia S, Fields BG. Sleep Telemedicine An Emerging Field 's Latest Frontier. Chest [Internet] 2016;149(6):1556-1565. Available from: https://doi.org/10. 1016/j.chest.2016.02.670.

18. Hoet F, Libert W, Sanida C, Broecke S Van Den, Bruyneel A V, Bruyneel M. AC SC. Sleep Med [Internet]. 2017; Available from: https://doi.org/10.1016/j. sleep.2017.08.016.

19. Fox NH-A, Goodfellow AJ, Wenner E, Fleetham J, Ryan J, Kwiatkowska CF, M Ayas $\mathrm{N}$. The impact of a telemedicine monitoring system on positive airway pressure adherence in patients with obstructive sleep apnea : a randomized controlled trial. Sleep. 2012;35(4):477-81.

20. Frasnelli M, Baty F, Niedermann J, Brutsche MH, Schoch OD. Effect of telemetric monitoring in the first 30 days of continuous positive airway pressure adaptation for obstructive sleep apnoea syndrome - a controlled pilot study. 2015;0(0):1-6.

21. Stepnowsky C, Palau J, Marler M, Gifford AL. Pilot Randomized Trial of the Effect of Wireless Telemonitoring on Compliance and Treatment Efficacy in Obstructive Sleep Apnea Methods. J Med Internet Search. 2007;9(2).

22. Farré R, Navajas D, Montserrat JM. Is telemedicine a key tool for improving continuous positive airway pressure adherence in patients with sleep apnea? Am J Respir Crit Care Med. 2018;197(1):12-4.

23. Müller $\mathrm{Kl}$, Alstadhaug KB, Bekkelund SI. A randomized trial of telemedicine efficacy and safety for nonacute headaches. Neurology. 2017;89(2):153-62.

24. Castelnuovo G, Manzoni GM, Cuzziol P, Cesa GL, Tuzzi C, Villa V, et al. TECNOB: study design of a randomized controlled trial of a multidisciplinary telecare intervention for obese patients with type-2 diabetes. BMC Public Health. 2010;10(1):204.

25. Vignatelli L, Plazzi G, Bassein L, Barbato A, De Vincentiis A, Lugaresi E, et al. ICSD diagnostic criteria for narcolepsy: Interobserver reliability. Sleep. 2002 25(2):193-6.

26. Fleiss JL, Levin B, Paik MC. Statistical methods for rates and proportions. john wiley \& sons; 2013.
27. Landis JR, Koch GG. The measurement of observer agreement for categorical data. Biometrics. 1977:159-74.

28. Vignatelli L, Plazzi G, Barbato A, Ferini-Strambi L, Manni R, Pompei F, et al. Italian version of the Epworth sleepiness scale: external validity. Neurol Sci. 2003;23(6):295-300.

29. Mannocci A, Di Thiene D, Del Cimmuto A, Masala D, Boccia A, De Vito E, et al. International Physical Activity Questionnaire: validation and assessment in an Italian sample. Ital J Public Health. 2010;7(4).

30. Dauvilliers Y, Bassetti C, Lammers GJ, Arnulf I, Mayer G, Rodenbeck A, et al. Pitolisant versus placebo or modafinil in patients with narcolepsy: a doubleblind, randomised trial. Lancet Neurol. 2013;12(11):1068-75.

31. Vignatelli L, Antelmi E, Ceretelli I, Bellini M, Carta C, Cortelli P, et al. Red flags for early referral of people with symptoms suggestive of narcolepsy: a report from a national multidisciplinary panel. Neurol Sci. 2019;40(3):447-56.

32. Janssen KC, Phillipson S, O'Connor J, Johns MW. Validation of the Epworth sleepiness scale for children and adolescents using Rasch analysis. Sleep Med. 2017:33:30-5.

33. Dauvilliers Y, Beziat S, Pesenti C, Lopez R, Barateau L, Carlander B, et al. Measurement of narcolepsy symptoms: the narcolepsy severity scale. Neurology. 2017;88(14):1358-65.

34. Beck AT, Ward C, Mendelson M, Mock J, Erbaugh J. Beck depression inventory (BDI). Arch Gen Psychiatry. 1961:4(6):561-71.

35. Spielberger CD, Gorsuch RL. State-trait anxiety inventory for adults. Mind Garden: Palo Alto, CA; 1983.

36. Finch AJ Jr, Saylor CF, Edwards GL, McIntosh JA. Children's depression inventory: reliability over repeated administrations. J Clin Child Psychol. 1987;16(4):339-41.

37. March JS, Parker JDA, Sullivan K, Stallings P, Conners CK. The multidimensional anxiety scale for children (MASC): factor structure, reliability, and validity. J Am Acad Child Adolesc Psychiatry. 1997;36(4):554-65.

38. Kadouri A, Corruble E, Falissard B. The improved clinical global impression scale (iCGI): development and validation in depression. BMC Psychiatry. 2007;7(1):7.

39. Apolone G, Mosconi P. The Italian SF-36 health survey: translation, validation and norming. J Clin Epidemiol. 1998:51(11):1025-36.

40. Varni JW, Seid M, Rode CA. The PedsQL ${ }^{\mathrm{TM}}$ : measurement model for the pediatric quality of life inventory. Med Care. 1999:126-39.

41. Solari A, Grzeda M, Giordano A, Mattarozzi K, D'Alessandro R, Simone A, et al. Use of Rasch analysis to refine a patient-reported questionnaire on satisfaction with communication of the multiple sclerosis diagnosis. Mult Scler J. 2014;20(9):1224-33

\section{Publisher's Note}

Springer Nature remains neutral with regard to jurisdictional claims in published maps and institutional affiliations.

Ready to submit your research? Choose BMC and benefit from:

- fast, convenient online submission

- thorough peer review by experienced researchers in your field

- rapid publication on acceptance

- support for research data, including large and complex data types

- gold Open Access which fosters wider collaboration and increased citations

- maximum visibility for your research: over $100 \mathrm{M}$ website views per year

At $\mathrm{BMC}$, research is always in progress.

Learn more biomedcentral.com/submission 